\title{
Electrochemical Behavior and Determination of Rutin on Modified Carbon Paste Electrodes
}

\author{
Pavla Macikova, ${ }^{1}$ Vladimir Halouzka, ${ }^{2}$ Jan Hrbac, ${ }^{2}$ Petr Bartak, ${ }^{1}$ and Jana Skopalova ${ }^{3}$ \\ ${ }^{1}$ Regional Centre of Advanced Technologies and Materials, Department of Analytical Chemistry, Faculty of Science, Palacky University, \\ 17. listopadu 12, 77146 Olomouc, Czech Republic \\ ${ }^{2}$ Department of Physical Chemistry, Faculty of Science, Palacky University, 17. listopadu 12, 77146 Olomouc, Czech Republic \\ ${ }^{3}$ Department of Analytical Chemistry, Faculty of Science, Palacky University, 17. listopadu 12, 77146 Olomouc, Czech Republic
}

Correspondence should be addressed to Jana Skopalova, jana.skopalova@upol.cz

Received 31 October 2011; Accepted 3 January 2012

Academic Editors: S. D’Ilio and F. Zhang

Copyright (C) 2012 Pavla Macikova et al. This is an open access article distributed under the Creative Commons Attribution License, which permits unrestricted use, distribution, and reproduction in any medium, provided the original work is properly cited.

\begin{abstract}
The performances of ionic liquid (1-hexyl-3-methylimidazolium-bis(trifluoromethylsulfonyl)imide, IL/CPE) and iron phthalocyanine (IP/CPE) modified carbon paste electrodes in electroanalytical determinations of rutin were evaluated and compared to the performance of unmodified carbon paste electrode (CPE). Cyclic voltammetry (CV), differential pulse voltammetry (DPV), differential pulse adsorptive stripping voltammetry (DPAdSV), and amperometry were used for rutin analysis. The best current responses of rutin were obtained at $\mathrm{pH} 4.0$ for all tested techniques. IL/CPE electrode was found to perform best with DPAdSV technique, where a detection limit (LOD) as low as $5 \mathrm{nmol} \mathrm{L}^{-1}$ of rutin was found. On the other hand, IP/CPE showed itself to be an optimum choice for DPV technique, where LOD of $80 \mathrm{nmol} \mathrm{L}^{-1}$ was obtained. Analytical applicability of newly prepared electrodes was demonstrated on determination of rutin in the model samples and the extracts of buckwheat seeds. To find an optimum method for buckwheat seeds extraction, a boiling water extraction (BWE), Soxhlet extraction (SE), pressurized solvent extraction (PSE), and supercritical fluid extraction (SFE) were tested.
\end{abstract}

\section{Introduction}

Rutin is a bioactive flavonoid. The structure of rutin (Figure 1) consists of an aglycone quercetin and a disaccharide rutinose bound to quercetin at a position 3 , ring $C$. It has a strong antioxidant activity as proved by different in vitro antioxidant assays [1]. Supplementation with rutin increases the total antioxidant status of blood plasma $[2,3]$.

Rutin is usually determined by high-performance liquid chromatography [4], capillary electrophoresis [5], spectrophotometry [6], and chemiluminescence [7] techniques. Due to the fact that rutin is an electroactive species, electrochemical techniques can also be successfully employed for this task. Electrochemical behaviour of rutin is characterized by two oxidative signals under the conditions similar to the internal environment of human metabolism. The first reversible anodic signal corresponds to two-electron oxidation of $-\mathrm{OH}$ groups at positions $3^{\prime}$ and $4^{\prime}$ forming an $o-$ quinone. The other irreversible anodic signal is presumably caused by oxidation on the ring A [8].
In the field of electroanalysis, modified carbon paste electrodes (MCPEs) can provide selectivity and sensitivity, resist fouling, concentrate species, improve electroanalytical properties, and limit access of interfering species often present in complex samples or biological fluids. A properly selected modifier can concentrate analyte on an electrode surface or serve as a catalyst of electrochemical reactions $[9,10]$. New and still more popular ways of CPE modification are ionic liquids (ILs), which consist of heterocyclic organic cation and various kinds of anions. ILs possess specific physicochemical properties such as excellent ionic conductivity, high chemical and thermal stability, inconsiderable vapor pressure, and wide electrochemical window [11-16].

Recently, ILs modified carbon paste electrodes have been applied for analysis of rutin. IL-CPEs containing bis(trifluoromethylsulfonyl)imide anion and different imidazolium cations along with laccase from Aspergillus oryzae (catalyst of rutin oxidation) allowed determination of micromolar amounts of rutin in pharmaceutical samples [17]. Zhang and 


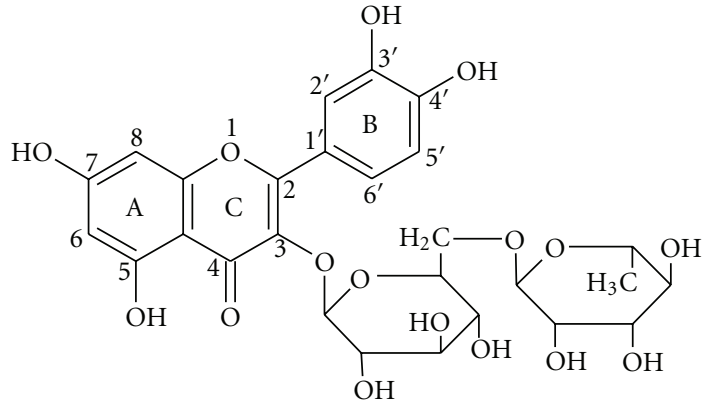

Figure 1: Chemical structure of rutin.

Zheng [18] availed an electrocatalytic activity of 1-amyl-3methylimidazolium bromide modified CPE toward the redox reactions of rutin to its successful quantification in tablets and urine samples. The detection limit of their electrode reached $1 \times 10^{-8} \mathrm{~mol} \mathrm{~L}^{-1}$ of rutin by square wave voltammetry (SWV). Likewise, N-butylpyridinium hexafluorophosphate modified CPE gave strong electrocatalytic effect to the oxidation of rutin [19] and allowed to quantify $3.5 \times$ $10^{-7} \mathrm{~mol} \mathrm{~L}^{-1}$ of rutin using cyclic voltammetry, a technique far less sensitive than SWV. DNA modified carbon paste electrode containing 1-butyl-3-methylimidazolium hexafluorophosphate ionic liquid and paraffin oil as a binder was used for sensitive detection of rutin [20]. Single-walled carbon nanotubes modified carbon paste electrode with ionic liquid (1-butyl-3-methylimidazolium tetrafluoroborate) was also successfully used for analysis of rutin with similar results [21].

Metals and metallic compounds are often admixed into carbon pastes for example, bismuth [22, 23], gold [24], iron compounds [25-28], manganese (IV) oxide [29, 30], copper (I) oxide [31], and so forth. Iron (II) phthalocyanine as a component of carbon paste electrode has been found to be an effective electrocatalyst of the reduction of organic peroxides [32] and oxidation water in alkaline medium [33]. Recently, it has been also recognized as an efficient electrocatalyst of epinephrine oxidation [34]. Similar electrocatalytic action was reported also for other neurotransmitters containing quinone moiety (dopamine and serotonin) [35]. This finding encouraged us to test the iron (II) phthalocyanine for its electrocatalytical action towards rutin.

In the present work, we prepared state of the art 1-hexyl-3-methylimidazolium-bis(trifluoromethylsulfonyl)imide $\left([\mathrm{hmim}]\left[\mathrm{Tf}_{2} \mathrm{~N}\right]\right)$ ionic liquid and iron phthalocyanine modified carbon paste electrodes and tested them in rutin solutions using cyclic voltammetry (CV), differential pulse voltammetry (DPV), differential pulse adsorptive stripping voltammetry (DPAdSV), and amperometry. For comparison purposes, analogical experiments were performed with unmodified carbon paste electrode to evaluate the accessible potential window, the background current, surface reproducibility, and the redox and surface behaviors of rutin. The electrodes were finally applied to rutin determination in extracts from buckwheat seeds (Fagopyrum esculentum Moench) by a standard addition method. Four extraction procedures were tested: boiling water extraction (BWE), Soxhlet extraction (SE), pressurized solvent extraction (PSE), and supercritical fluid extraction (SFE) of buckwheat seeds.

\section{Experimental}

2.1. Reagents. Carbon pastes were prepared from graphite flakes (Aldrich-Chemie, Steinheim, Germany) and paraffin oil (pharmaceutical grade) or 1-hexyl-3-methylimidazolium-bis(trifluoromethylsulfonyl) imide ([hmim] $\left.\left[\mathrm{Tf}_{2} \mathrm{~N}\right]\right)(\geq$ 98.0\%, Merck, Darmstadt, Germany). Iron (II) phthalocyanine ( $\geq 97 \%$, Fluka Chemie, Buchs, Switzerland) served as carbon paste modifier. Rutin hydrate ( $\geq 94 \%$, Sigma-Aldrich Chemie, Steinheim, Germany) was used without further treatment. Standard solution of rutin $(1.0 \mathrm{mM})$ was prepared in methanol (p.a., LachNer, Czech Republic). More diluted solutions were obtained by dilution with redistilled water. Britton-Robinson buffers were prepared from trihydrogen phosphoric acid, acetic acid and trihydrogen boric acid (0.04 $\mathrm{M}$ each). Desired $\mathrm{pH}$ values were adjusted with sodium hydroxide $(0.2 \mathrm{M})$. Ionic strength of B-R buffers was adjusted to $I=0.15$ with sodium perchlorate (p.a., Fluka Chemie, Buchs, Switzerland). Acetate buffer was prepared by titration of acetic acid $(0.1 \mathrm{M})$ with sodium hydroxide $(0.2 \mathrm{M})$. All chemicals used to prepare buffers (Lachema, Czech Republic) and acetone (p.a., Penta, Czech Republic) were of analytical grade. Doubly distilled water (Elga, UK) was used in all experiments. Hulled buckwheat seeds were obtained from PROBIO (Czech Republic).

2.2. Apparatus. Voltammetric measurements were performed on an Eco-Tribo Polarograph (Polaro-Sensors, Prague, Czech Republic) with Polar 4 software (Polaro-Sensors, Prague, Czech Republic). A three-electrode system involved $\mathrm{Ag} / \mathrm{AgCl} / 1 \mathrm{M}-\mathrm{KCl}$ reference electrode, a platinum wire auxiliary electrode and carbon paste electrodes were used as working electrodes. When needed, the measured solutions were purged with nitrogen.

Amperometric measurements in stirred solution were done using CHI660 electrochemical workstation (CH Instruments, USA).

UV/VIS spectrophotometer Lambda 25 (Perkin Elmer, USA) was used for the determination of dissociation constant of rutin. $\mathrm{pH}$ measurements were done using inoLab 720 (WTW, Germany) pH-meter. A supercritical fluid extractor SEKO-K (SEKO-K, Czech Republic), a pressurized solvent extractor one PSE (Applied Separations, USA) and Eppendorf AG 5702 centrifuge (Eppendorf AG, Germany) were used for rutin extractions from buckwheat seeds.

An analytical balance (Kern model ALS 220-4, Kern \& Sohn, Balingen, Germany) was used to weigh samples of buckwheat seeds and chemicals for preparation of solutions and carbon pastes.

Comparative measurements of rutin content in buckwheat extracts were performed on an HPLC system Waters (600S Controller), which consisted of a UV/Vis detector (type 486), a pump (type 616), and a $20 \mu \mathrm{L}$ loop. The 
detection wavelength was set to $236 \mathrm{~nm}$. The system was operated at room temperature. The analytical column was Tessek (C18, $205 \mathrm{~mm} \times 4.0 \mathrm{~mm}$ I.D., $5.0 \mu \mathrm{m}$, Separon). The mobile phase consisted of methanol $(55 \%)$, doubly distilled water (44\%), and acetic acid (1\%), the flow rate was $0.4 \mathrm{~mL} / \mathrm{min}$. The data were collected and evaluated by Clarity software (DataApex, Czech Republic).

2.3. The Preparation of Carbon Paste Working Electrodes. The carbon paste was prepared by mixing $200 \mathrm{mg}$ of graphite flakes with $80 \mu \mathrm{L}$ of paraffin oil. CPE modified with iron phthalocyanine (IP/CPE) was prepared by replacement of $10 \%$ (by weight) of graphite flakes by iron (II) phthalocyanine. Ionic liquid CPE (IL/CPE) was prepared from $200 \mathrm{mg}$ graphite and $100 \mu \mathrm{L}[\mathrm{hmim}]\left[\mathrm{Tf}_{2} \mathrm{~N}\right]$. Each mixture was homogenized in an agate mortar until a cohesive substance was formed. The paste was filled into the teflon electrode body equipped with a piston (inner diameter $2 \mathrm{~mm}$ ). The electrode surface was renewed before each scan by removing a small amount of paste from the electrode reservoir using a piston and polishing the electrode surface with a smooth paper.

2.4. Procedures. Cyclic voltammograms were recorded at scan rate $100 \mathrm{mV} \mathrm{s}^{-1}$. DPV experiments were performed at $50 \mathrm{mV}$ pulse amplitude, pulse width was $100 \mathrm{~ms}$, and scan rate $20 \mathrm{mV} \mathrm{s}^{-1}$. In both DPV and DPAdSV analysis limits of detection and quantification were determined experimentally as a concentration of rutin, the current response of which three-times (LOD) and ten-times (LOQ) exceeded the signal noise of supporting electrolyte current measured in the potential range of $E_{p} \pm 100 \mathrm{mV}$, where $E_{p}$ is a peak potential of rutin. The first oxidation peak of rutin was always evaluated. The precision and accuracy of the measurement were evaluated from the model samples of rutin prepared by adding $2 \mathrm{~mL}, 0.4 \mathrm{~mL}$ and $0.06 \mathrm{~mL}$ of rutin standard solution $(1 \mathrm{mM})$, respectively, to acetate buffer ( $\mathrm{pH} 4.0$ ) in distilled water of total volume of $1000 \mathrm{~mL}$. A volume of $10 \mathrm{~mL}$ was transferred into voltammetric vessel and analyzed using the standard addition method. Three additions of rutin standard solution $(0.1 \mathrm{mM})$ were used. Number of replicated measurements of each model sample was $n=5$. The HPLC method used for comparative measurement of rutin in model samples and buckwheat extracts was adapted from the literature [36].

Spectrophotometric determination of dissociation constant $(\mathrm{p} K)$ of rutin was carried out at rutin concentration of $0.2 \mu \mathrm{M}$. Ionic strengths of rutin solutions were adjusted to $0.15 \mathrm{M}$ with sodium perchlorate. The $\mathrm{p} K$ value of rutin was calculated from the measured data using the procedure described in [37].

Amperometric measurements were carried out at constant potential of $600 \mathrm{mV}$ versus $\mathrm{Ag} / \mathrm{AgCl}$. The aliquots $(50 \mu \mathrm{L})$ of rutin standard solution $(1 \mathrm{mM})$ were introduced into electrochemical cell containing $20 \mathrm{~mL}$ of supporting electrolyte using a home-made autosampler. Limits of detection were evaluated from calibration curves with QCExpert software (TriloByte, Czech Republic) by the IUPAC recommended direct method of signal [38].

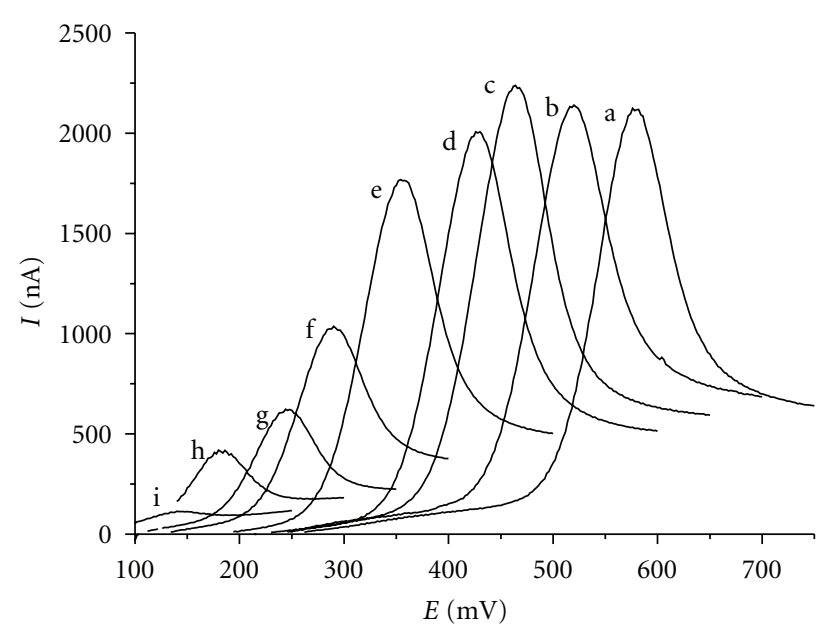

FIGURE 2: Linear sweep voltammogramms of $0.1 \mathrm{mM}$ rutin in Britton-Robinson buffers measured on CPE at scan rate of $100 \mathrm{mV} \mathrm{s}^{-1}$. (a) $\mathrm{pH} 2$, (b) $\mathrm{pH} \mathrm{3,} \mathrm{(c)} \mathrm{pH} 4$, (d) $\mathrm{pH} 5$, (e) $\mathrm{pH}$ 6, (f) $\mathrm{pH}$ 7, (g) $\mathrm{pH} 8$, (h) $\mathrm{pH} 9$, (i) $\mathrm{pH} 9.5$.

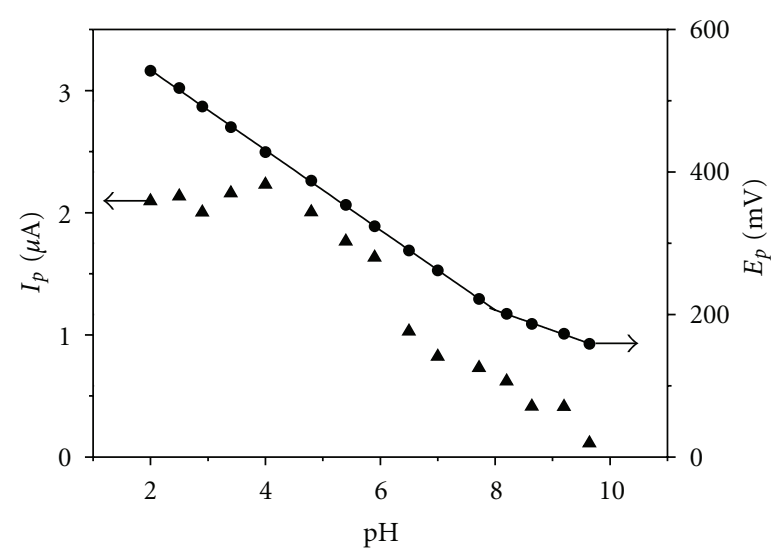

Figure 3: Dependence of anodic CV peak potential and peak current of rutin $\left(c=0.1 \mathrm{mmol} \mathrm{L}^{-1}\right)$ on $\mathrm{pH}$. The conditions of the experiments are given in the legend to Figure 2.

2.5. Buckwheat Extracts Preparation. Grinded buckwheat seeds ( 1 or $2 \mathrm{~g}$ weighed with analytical precision) were used to prepare extracts. Boiling water extraction (BWE) was performed by refluxing of the grinded buckwheat seeds for five minutes in $40 \mathrm{~mL}$ of double-distilled water. Extract was filled up to $50 \mathrm{~mL}$ with double-distilled water. Samples were centrifuged for 20 minutes and then filtered before analysis. Soxhlet extraction (SE) ran with methanol for four hours. This extract was filled up to $50 \mathrm{~mL}$ with methanol. Pressurized solvent extraction (PSE) was carried out with acetone at 150 bar pressure and temperature of $100^{\circ} \mathrm{C}$. Two 10 -minute cycles of static extraction were performed. This extract was filled up to $50 \mathrm{~mL}$ with acetone. Supercritical fluid extraction (SFE) with carbon dioxide proceeded under following conditions: pressure $25 \mathrm{MPa}$, temperature of an extraction cell $35^{\circ} \mathrm{C}$, temperature of a restrictor $100^{\circ} \mathrm{C}$, temperature of a catch $30^{\circ} \mathrm{C}$, time of analysis $30 \mathrm{~min}$ and acetone as a solvent. 


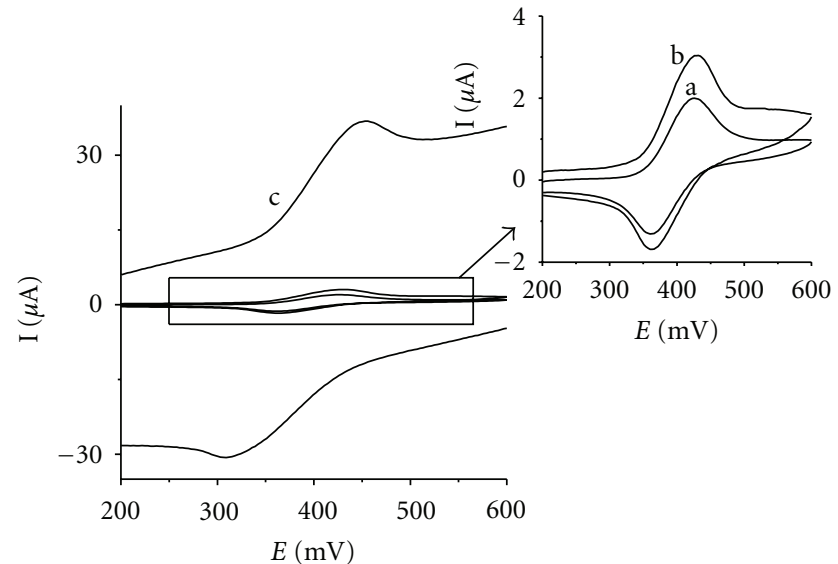

FIGURE 4: Cyclic voltammograms of rutin on IP/CPE (a), CPE (b), and IL/CPE (c). $0.1 \mathrm{mM}$ rutin solution in acetate buffer $(\mathrm{pH} 4.0)$, scan rate $100 \mathrm{mV} \mathrm{s}^{-1}$.

\section{Results and Discussion}

3.1. CV Experiments. As mentioned in Section 1 of this paper, anodic oxidation of rutin proceeds in two subsequent steps. From the point of view of the analytical usability, the first redox transition is more important, therefore further experiments are restricted to this process. In the cyclic voltammogram (Figure 2), the first redox transition manifests itself as a quasireversible, $\mathrm{pH}$-dependent electrode process. The potential of the anodic CV peak shifts to lower values with decreasing acidity (Figure 3 ). Two regression straight lines fitted to the $E_{p}-\mathrm{pH}$ data have slopes of -56 and $-29 \mathrm{mV} / \mathrm{pH}$ unit. This is consistent with the twoelectron oxidation involving the loss of two and one proton, respectively. The intersection point of the two lines at $\mathrm{pH} 8.0$ corresponds to an apparent dissociation constant of rutin. The $\mathrm{p} K$ value, estimated by us spectrophotometrically at the wavelength of $352 \mathrm{~nm}$ to be $\mathrm{p} K=7.14$, is in agreement with the published value of $\mathrm{p} K=7.1$ [39] which is supposed to represent the dissociation of the hydroxyl group in position $4^{\prime}$ of the ring $\mathrm{B}$.

The peak current is maximal in acidic media $(\mathrm{pH}<5)$ and decreases with increasing $\mathrm{pH}$ until it falls to zero at $\mathrm{pH}>10$ (Figure 3). The highest CV peak was obtained at $\mathrm{pH}=4$, therefore this acidity was chosen for all subsequent experiments.

To characterize the prepared electrodes, initial experiments have been made to compare the accessible potential window and the background charging current. According to expectations the IL/CPE displayed the widest potential window $(2.5 \mathrm{~V})$, compared to $\mathrm{CPE}(1.5 \mathrm{~V})$ and IP/CPE $(1.3 \mathrm{~V})$. IL/CPE had also the largest background current (about 60 times higher than that for CPE and IP/CPE). These large background charging currents are typical for electrodes with ionic liquid as a binder [12, 40].

All three electrodes gave quasireversible cyclic voltammograms of rutin differing in peak currents and peak separation values (Figure 4, Table 1). The overvoltage for the redox reaction grows at the tested electrodes in the order IP/CPE <

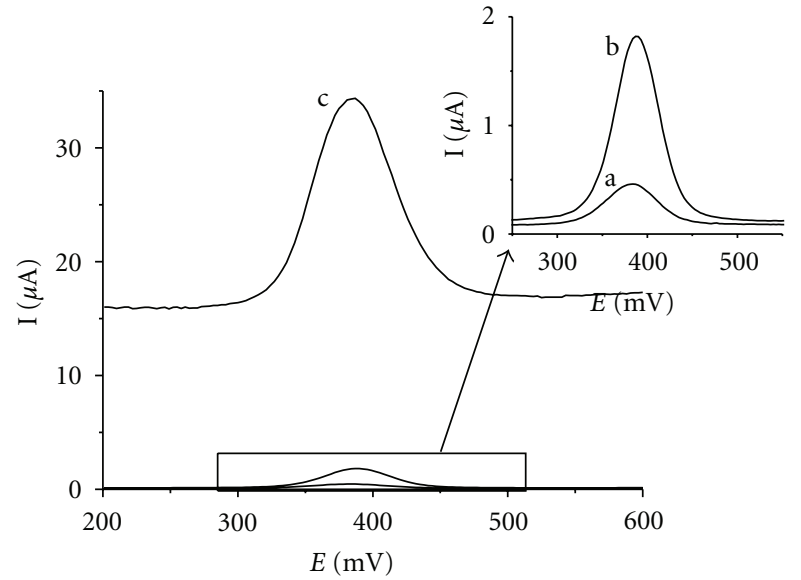

FIGURE 5: Differential pulse voltammograms of rutin on IP/CPE (a), CPE (b), and IL/CPE (c). $0.008 \mathrm{mM}$ rutin solution in acetate buffer ( $\mathrm{pH} 4.0$ ), scan rate $20 \mathrm{mV} \mathrm{s}^{-1}$, pulse amplitude $50 \mathrm{mV}$, and pulse width $100 \mathrm{~ms}$.

TABle 1: Potentials of anodic $\left(E_{p a}\right)$ and cathodic $\left(E_{p c}\right)$ peak (versus $\mathrm{Ag} / \mathrm{AgCl}, 1 \mathrm{M} \mathrm{KCl})$, peak separation $\left(\Delta E_{p}\right)$, anodic peak current $\left(i_{a}\right.$, the average from seven repeated measurements, standard deviation SD) and ratio of cathodic to anodic peak current $\left(i_{c} / i_{a}\right)$ of $0.1 \mathrm{mM}$ rutin at the paraffin/graphite (CPE), paraffin/ironphthalocyanine/graphite (IP/CPE) and $[\mathrm{hmim}]\left[\mathrm{Tf}_{2} \mathrm{~N}\right] /$ graphite (IL/CPE) electrodes (scan rate $100 \mathrm{mV} \mathrm{s}^{-1}$ ).

\begin{tabular}{lccccc}
\hline & $E_{\mathrm{pa}}(\mathrm{mV})$ & $E_{\mathrm{pc}}(\mathrm{mV})$ & $\Delta E_{p}(\mathrm{mV})$ & $i_{a} \pm \mathrm{SD}(\mu \mathrm{A})$ & $i_{c} / i_{a}$ \\
\hline $\mathrm{CPE}$ & 429 & 363 & 66 & $2.2 \pm 0.02$ & 0.65 \\
$\mathrm{IP} / \mathrm{CPE}$ & 427 & 367 & 60 & $1.6 \pm 0.02$ & 0.76 \\
$\mathrm{IL} / \mathrm{CPE}$ & 450 & 318 & 132 & $21.5 \pm 0.32$ & 0.66 \\
\hline
\end{tabular}

$\mathrm{CPE} \ll \mathrm{IL} / \mathrm{CPE}$. Simultaneously, the highest ratio of cathodic to anodic peak current demonstrates better reversibility on IP/CPE as compared to CPE and IL/CPE. This means that iron (II) phthalocyanine catalyzed the oxidation of rutin, similarly to other phenols and polyphenols [41, 42]. The peak current of rutin is almost ten-times higher on IL/CPE in comparison to CPE. However, the peak separation inferior to unmodified CPE and a comparable ratio of cathodic to anodic peak indicate that higher current is not caused by electrocatalytic effect of IL/CPE but is rather caused by increased electroactive area of the IL/CPE. This opinion is supported by the fact that background current is increased as well for IL/CPE compared to CPE.

3.2. DPV and DPAdSV Experiments. Similarly to CV, the highest DPV peak of rutin was observed on IL/CPE (Figure 5, curve c). Ionic liquid-based electrode provided more than tenfold increase in signal compared to the CPE. Moreover, due to the capability of DPV method to discriminate against the capacitive background current the rutin DPV peaks on IL/CPE are well evaluable and usable for analytical purposes.

We observed a strong adsorption of rutin on all three tested electrodes. First, we tested the adsorption of rutin onto electrode surfaces in an open circuit. The electrodes were dipped into $2 \mu \mathrm{M}$ rutin solution. After an accumulation 


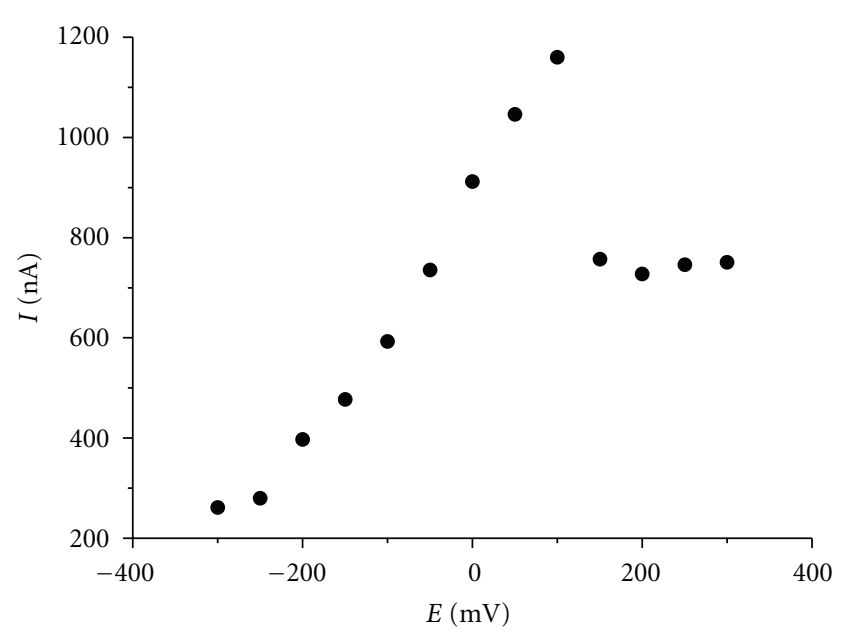

(a)

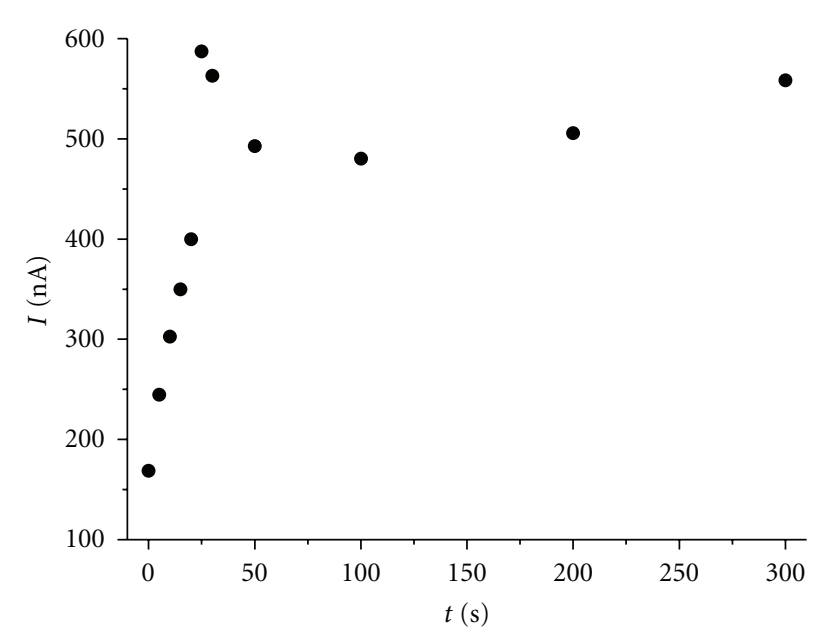

(b)

FIgURE 6: Dependences of DPV peak heights of $2 \mu \mathrm{M}$ rutin solution in acetate buffer ( $\mathrm{pH} 4.0)$ at (a) accumulation potential at $t_{\mathrm{acc}}=25 \mathrm{~s}$ and (b) accumulation time $\left(E_{\text {acc }}=+100 \mathrm{mV}\right)$. DPV parameters: scan rate $20 \mathrm{mV} \mathrm{s}^{-1}$, pulse amplitude $50 \mathrm{mV}$, and pulse width $100 \mathrm{~ms}$.

TABLE 2: Parameters of calibration regression straight lines and limits of detection (LOD) and quantification (LOQ) of rutin on the tested carbon paste electrodes, DPAdSV measurement.

\begin{tabular}{lccccc}
\hline Electrode & $\left.c(\mu \mathrm{mol} \mathrm{L})^{-1}\right)$ & Regression equation $y=a x+b$ & $R$ & $\mathrm{LOD}\left(\mathrm{mol} \mathrm{L}^{-1}\right)$ & $\mathrm{LOQ}^{\left(\mathrm{mol} \mathrm{L}^{-1}\right)}$ \\
\hline $\mathrm{CPE}$ & $0.01-0.1$ & $y=5 \times 10^{8} x-2.15$ & 0.9784 & $1 \times 10^{-8}$ & $3 \times 10^{-8}$ \\
& $0.2-1$ & $y=9 \times 10^{8} x-171.27$ & 0.9886 & $5 \times 10^{-9}$ & $2 \times 10^{-8}$ \\
IL/CPE & $0.005-0.08$ & $y=5 \times 10^{9} x+171.95$ & 0.9852 & 0.9935 & $2 \times 10^{-8}$ \\
IP/CPE & $0.02-0.6$ & $y=8 \times 10^{8} x-13.75$ & $6 \times 10^{-8}$ \\
\hline
\end{tabular}

$c$ : linear concentration range, $R$ : correlation coefficient.

period of $5 \mathrm{~min}$, the electrodes were washed with doubly distilled water and placed in an electrochemical cell with supporting electrolyte. A peak of rutin was observed for all electrodes and its height corresponded to $77 \%, 64 \%$, and $50 \%$ of the peak height determined in $2 \mu \mathrm{M}$ rutin solution on the CPE, IL/CPE and IP/CPE, respectively. No signal of rutin was detected in the supporting electrolyte after renewing surfaces of electrodes. This observation gives the evidence that the electrolyte was not contaminated by the analyte and rutin did not diffuse deeper into the bulk of the electrode material. Subsequently, the dependence of rutin response on accumulation potential and time was examined using DPAdSV. The accumulation in $2 \mu \mathrm{M}$ rutin solution was the most effective at the potential of $+100 \mathrm{mV}$ and time of $25 \mathrm{~s}$ (Figure 6). Similar dependences were obtained for all three electrodes.

Calibration dependences of rutin measured by DPV with all three tested electrodes reflect the rutin adsorption. Both DPV and DPAdSV methods give calibration curves linear only in micromolar concentration ranges and nonlinear at higher concentrations. Lower detection limits and narrower linear concentration ranges were typical for DPAdSV. Interestingly, IL/CPE exhibited the best performance in DPAdSV mode, where a very low $\operatorname{LOD}\left(5 \mathrm{nmol} \mathrm{L}^{-1}\right)$ was found (Table 2). On the other hand, in the case of DPV technique the lowest LOD value was found for IP/CPE (Table 3 ).
The standard addition method was preferred for the analysis of model samples. Determination of rutin was carried out using both DPV and DPAdSV methods for all three electrodes at three concentration levels $(0.06,0.4$, and $2.0 \mu \mathrm{mol} \mathrm{L} \mathrm{L}^{-1}$ of rutin) with three additions of standard solution. Results are summarized in Table 4. All determinations were precise and accurate at the 95\% confidence level. Measurement bias was statistically insignificant. Comparative measurements were performed by HPLC-UV/VIS method with $2.0 \mu \mathrm{M}$ rutin solution measured in five replicates. The relative standard deviation $s_{r}=4.3 \%$ and the percentage bias $B=3.5 \%$ are comparable to values obtained for voltammetric measurements.

3.3. Amperometry. After repeated injections of rutin standard solutions an increased noise in the corresponding amperometric response appeared for all electrodes, which may be caused by adsorption of rutin or its oxidation products on the electrode surface (Figure 7). The highest level of noise even in low rutin concentration of $5 \mu \mathrm{mol} \mathrm{L}^{-1}$ exhibited the IL/CPE electrode, which made the amperogram difficult to evaluate. We have found that significant improvement of signal-to-noise ratio is achieved, if pulse technique involving a cleaning step at $-300 \mathrm{mV}$ for $30 \mathrm{~s}$ is used (Figure 8). The detection limits using the pulsed technique were $0.20 \mu \mathrm{mol} \mathrm{L}^{-1}$ for unmodified CPE, somewhat 
TABle 3: Parameters of calibration regression straight lines and limits of detection (LOD) and quantification (LOQ) of rutin on the tested carbon paste electrodes, DPV measurement.

\begin{tabular}{lccccc}
\hline Electrode & $c\left(\mu \mathrm{mol} \mathrm{L}{ }^{-1}\right)$ & Regression equation $y=a x+b$ & $R$ & ${\mathrm{LOD}\left(\mathrm{mol} \mathrm{L}^{-1}\right)}_{\mathrm{LOQ}\left(\mathrm{mol} \mathrm{L}^{-1}\right)}$ \\
\hline CPE & $0.2-8$ & $y=2 \times 10^{8} x-41.90$ & 0.9911 & $2 \times 10^{-7}$ & $7 \times 10^{-7}$ \\
IL/CPE & $0.6-6$ & $y=3 \times 10^{8} x+41.89$ & 0.9944 & $6 \times 10^{-7}$ & $2 \times 10^{-6}$ \\
IP/CPE & $0.08-6$ & $y=2 \times 10^{8} x-9.64$ & 0.9955 & $8 \times 10^{-8}$ & $3 \times 10^{-7}$ \\
\hline
\end{tabular}

$c$ : linear concentration range, $R$ : correlation coefficient.

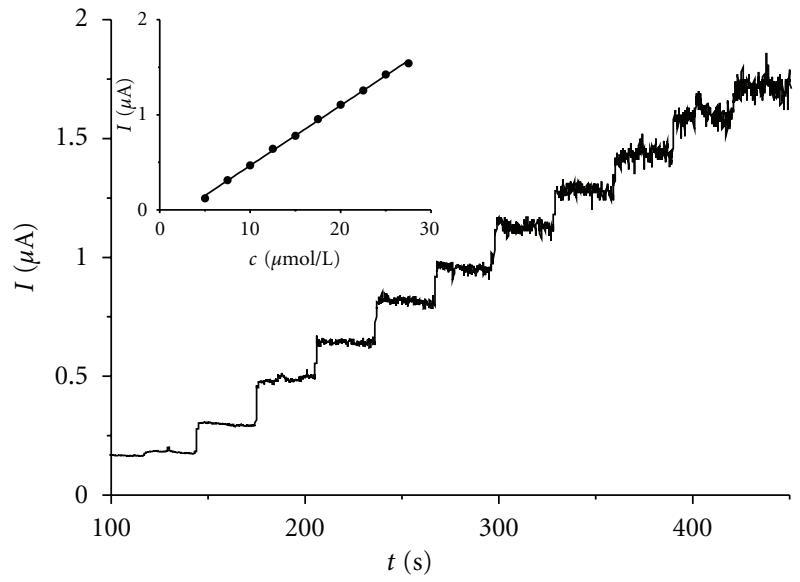

(a)

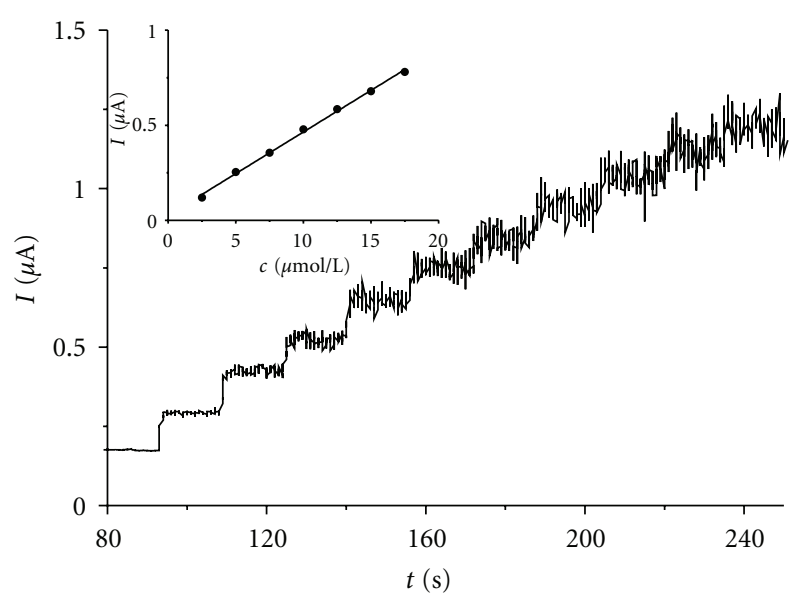

(b)

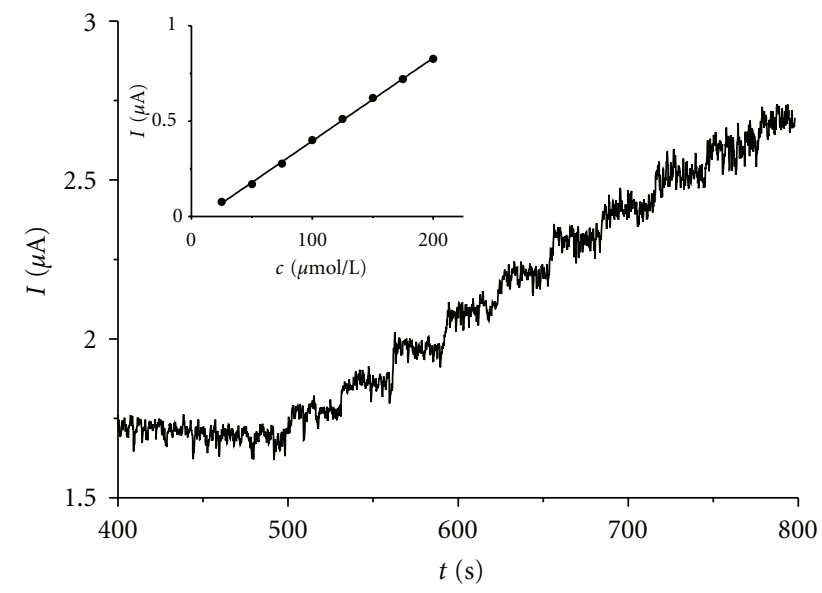

(c)

Figure 7: Amperograms and corresponding calibration curves (in insets) of rutin on unmodified (a), iron phthalocyanine modified (b) and ionic liquid modified (c) CPE at $500 \mathrm{mV}$.

higher for IP/CPE $\left(0.50 \mu \mathrm{mol} \mathrm{L}{ }^{-1}\right)$ and ten-times higher detection limit was determined for IL/CPE $\left(3.05 \mu \mathrm{mol} \mathrm{L}{ }^{-1}\right)$. The broadest linear concentration range was found for unmodified CPE $\left(0.25-3.1 \mu \mathrm{mol} \mathrm{L}^{-1}\right)$, than IP/CPE $(2.5-$ $24.3 \mu \mathrm{mol} \mathrm{L}{ }^{-1}$ ), and the narrowest one was found for IL/CPE $(2.5-12.3 \mu \mathrm{mol} \mathrm{L}-1)$, see Figure 8 .

3.4. Rutin Determination in Buckwheat Extracts. Four extraction techniques (boiling water extraction, BWE, Soxhlet extraction, SE, pressurized solvent extraction, PSE, and supercritical fluid extraction, SFE) were tested to find an optimum method for isolation of rutin from buckwheat seeds. DPV without accumulation was used as analytical method. No signal of rutin was obtained in extracts from SFE suggesting the used solvent (supercritical $\mathrm{CO}_{2}$ ) is inadvisable for this type of analyte. In PSE extracts, an anodic peak with a potential about $0.1 \mathrm{~V}$ lower than that of rutin was observed. This signal corresponded most likely to oxidation of flavonol quercetin as verified by an addition of quercetin standard solution into the measured PSE extract which caused an increase of the peak. The presence of quercetin instead of rutin could be explained either by hydrolysis of rutin to its aglycone or, which is more probable, preferential extraction of less polar quercetin with less polar solvent (acetone). On 

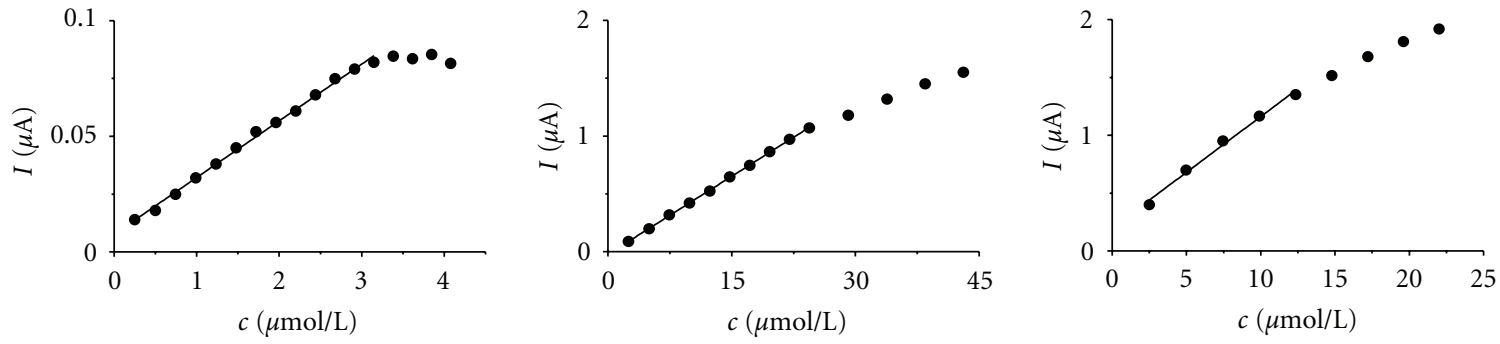

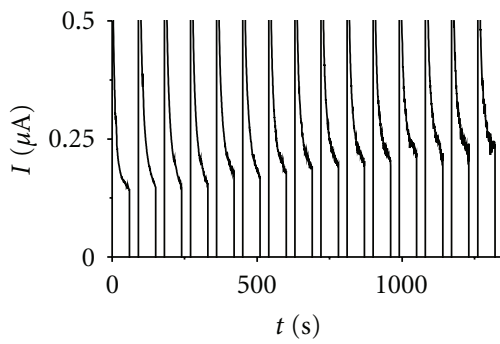

(a)

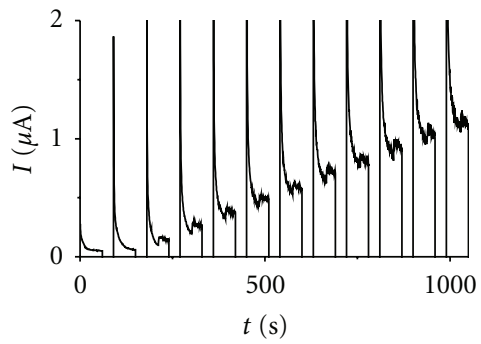

(b)

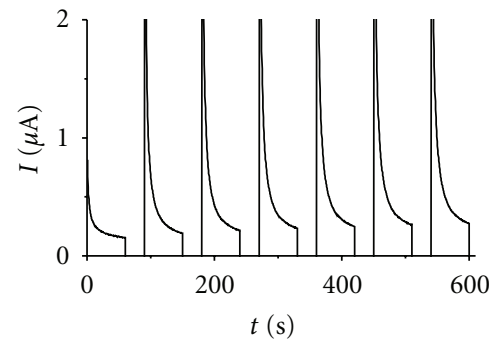

(c)

FIGURE 8: Pulse amperograms (the currents flowing during cleaning step are removed from the amperograms) and corresponding calibration curves of rutin on unmodified (a), iron phthalocyanine modified (b) and ionic liquid modified (c) CPE. The potential was set to $+600 \mathrm{mV}$ for $60 \mathrm{~s}$, current was sampled at this point. A $30 \mathrm{~s}$ cleaning step at $-300 \mathrm{mV}$ followed, during which aliquots of rutin sample solution were introduced into the measuring cell.

TABLE 4: DPV and DPAdSV determination of rutin in model samples using the method of standard additions. Number of repeated measurements $n=5$.

\begin{tabular}{|c|c|c|c|c|c|}
\hline Method of measuring & Electrode & $\begin{array}{l}\text { Mean content of rutin } \\
\left.(\mu \mathrm{mol} \mathrm{L})^{-1}\right)\end{array}$ & $\begin{array}{l}\text { Relative standard } \\
\text { deviation } s_{r}(\%)\end{array}$ & Measurement bias B (\%) & Recovery $R(\%)$ \\
\hline \multirow{5}{*}{ DPV } & \multirow{2}{*}{$\mathrm{CPE}$} & 1.99 & 2.6 & -0.74 & 99.3 \\
\hline & & 0.42 & 4.3 & 5.06 & 105.1 \\
\hline & IL/CPE & 2.07 & 6.3 & 3.58 & 103.6 \\
\hline & \multirow{2}{*}{$\mathrm{IP} / \mathrm{CPE}$} & 2.01 & 4.7 & 0.31 & 100.3 \\
\hline & & 0.40 & 4.5 & 0.98 & 101.0 \\
\hline \multirow{6}{*}{ DPAdSV } & \multirow{2}{*}{$\mathrm{CPE}$} & 0.057 & 4.9 & -5.53 & 94.5 \\
\hline & & 0.39 & 3.6 & -2.85 & 97.2 \\
\hline & \multirow{2}{*}{ IL/CPE } & 0.064 & 9.1 & 7.27 & 107.3 \\
\hline & & 0.42 & 6.8 & 4.10 & 104.1 \\
\hline & \multirow{2}{*}{$\mathrm{IP} / \mathrm{CPE}$} & 0.063 & 5.4 & 4.50 & 104.5 \\
\hline & & 0.41 & 5.1 & 1.51 & 101.5 \\
\hline
\end{tabular}

the other hand, in extracts prepared by BWE and SE only the rutin peak was detected.

The quantification of rutin in BWE extract by the method of standard addition (Figure 9) gave $11.8 \mathrm{mg}, 12.3 \mathrm{mg}$, and $11.0 \mathrm{mg}$ of rutin per $100 \mathrm{~g}$ of dried buckwheat seeds on $\mathrm{CPE}$, IP/CPE, and IL/CPE, respectively. Comparative measurements by HPLC with UV detection gave the result of $11.4 \mathrm{mg}$ of rutin per $100 \mathrm{~g}$ of dried buckwheat seeds. Our results are consistent with the published content of rutin in buckwheat seeds $(13.6 \mathrm{mg} / 100 \mathrm{~g},[43])$.

\section{Conclusions}

The electroanalytical behaviour of rutin on two modified CPEs and unmodified CPE was studied in this paper.
Iron (II) phthalocyanine as a CPE modifier revealed an electrocatalytic effect on the rutin oxidation. The excellent performance of the carbon paste electrode modified with ionic liquid $[\mathrm{hmim}]\left[\mathrm{Tf}_{2} \mathrm{~N}\right]$ was found for rutin determination using DPV technique. Strong adsorption of rutin observed on all electrode materials can be used for sensitivity improvement of voltammetric analysis by DPAdSV. With this technique, limits of detection found with the modified electrodes achieved the nanomolar concentration level. Ionic liquid as a modifier decreased limit of rutin detection in DPAdSV method while iron (II) phthalocyanine lowered LOD in DPV compared to unmodified CPE. Voltammetric methods could be a low-cost and highly sensitive alternative to much more expensive HPLC methods. Noise issues were observed which limit the usability of the studied electrodes 


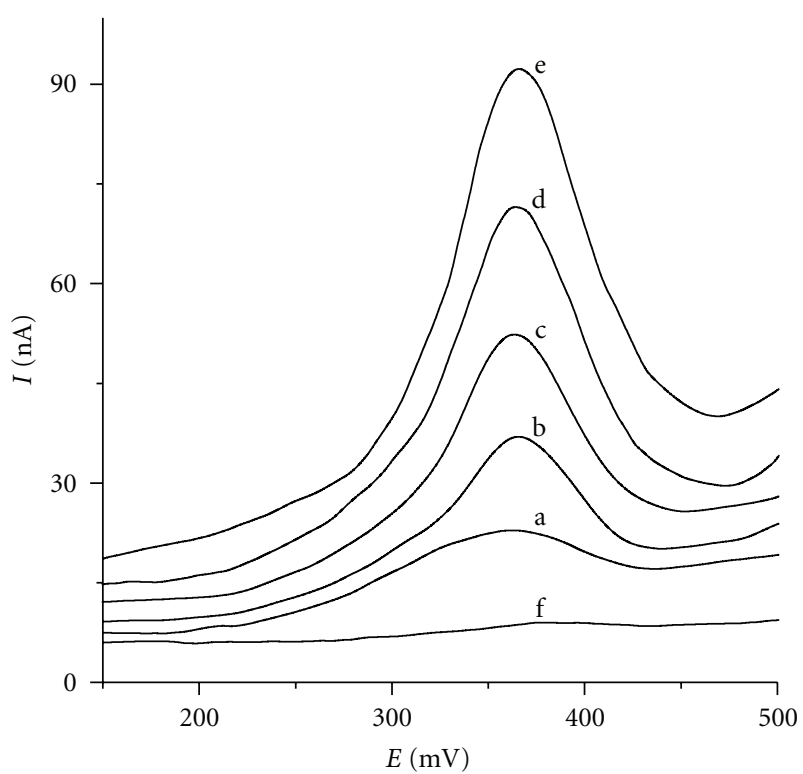

Figure 9: Differential pulse voltammograms of tenfold diluted boiling water extract of buckwheat seeds (a) at IP/CPE and four standard additions of rutin: $20 \mathrm{nmol}$ (b), $40 \mathrm{nmol}$ (c), $60 \mathrm{nmol}$ (d), and $80 \mathrm{nmol}(\mathrm{e})$ in acetate buffer $\mathrm{pH}=4$ as supporting electrolyte (f).

to determine rutin by constant potential amperometry in stirred solution. To overcome this problem, a pulse amperometric method was suggested, which achieved a detection limit in submicromolar concentration level of rutin using unmodified CPE. All three studied carbon paste electrodes are usable for analysis of rutin in real samples as has been demonstrated on the analysis of buckwheat seeds extracts.

\section{Acknowledgments}

The authors gratefully acknowledge the support by the Ministry of Education, Youth and Sports of the Czech Republic (Projects CZ.1.05/2.1.00/03.0058 of Operational Program Research and Development for Innovations-European Social Fund and MSM6198959216). The paper has been also supported by the project of Palacky University in Olomouc PRF_2011_025.

\section{References}

[1] J. Yang, J. Guo, and J. Yuan, "In vitro antioxidant properties of rutin," LWT_Food Science and Technology, vol. 41, no. 6, pp. 1060-1066, 2008.

[2] E. Florek, E. Ignatowicz, J. Wrzosek, and W. Piekoszewski, "Effect of rutin on total antioxidant status of rats exposed to cigarette smoke," Pharmacological Reports, vol. 57, no. 1, pp. 84-89, 2005.

[3] T. Bojňanská, H. Frančáková, P. Chlebo, and A. Vollmannová, "Rutin content in buckwheat enriched bread and influence of its consumption on plasma total antioxidant status," Czech Journal of Food Sciences, vol. 27, pp. S236-S240, 2009.

[4] Q. Liu, W. Cai, and X. Shao, "Determination of seven polyphenols in water by high performance liquid chromatography combined with preconcentration," Talanta, vol. 77, no. 2, pp. 679-683, 2008.

[5] G. Chen, H. Zhang, and J. Ye, "Determination of rutin and quercetin in plants by capillary electrophoresis with electrochemical detection," Analytica Chimica Acta, vol. 423, no. 1, pp. 69-76, 2000.

[6] H. N. A. Hassan, B. N. Barsoum, and I. H. I. Habib, "Simultaneous spectrophotometric determination of rutin, quercetin and ascorbic acid in drugs using a Kalman Filter approach," Journal of Pharmaceutical and Biomedical Analysis, vol. 20, no. 1-2, pp. 315-320, 1999.

[7] Z. Song and S. Hou, "Sensitive determination of subnanogram amounts of rutin by its inhibition on chemiluminescence with immobilized reagents," Talanta, vol. 57, no. 1, pp. 59-67, 2002.

[8] M. E. Ghica and A. M. O. Brett, "Electrochemical oxidation of rutin,” Electroanalysis, vol. 17, no. 4, pp. 313-318, 2005.

[9] R. C. Alkire, D. M. Kolb, J. Lipkowski, and P. Ross, Chemically Modified Electrodes, Wiley, Weinheim, Germany, 2009.

[10] K. Kalcher, "Chemically modified carbon paste electrodes in voltammetric analysis," Electroanal, vol. 2, pp. 419-433, 1990.

[11] Y. Zhang and J. B. Zheng, "Comparative investigation on electrochemical behavior of hydroquinone at carbon ionic liquid electrode, ionic liquid modified carbon paste electrode and carbon paste electrode," Electrochimica Acta, vol. 52, no. 25, pp. 7210-7216, 2007.

[12] M. Musameh and J. Wang, "Sensitive and stable amperometric measurements at ionic liquid-carbon paste microelectrodes," Analytica Chimica Acta, vol. 606, no. 1, pp. 45-49, 2008.

[13] N. Maleki, A. Safavi, and F. Tajabadi, "Investigation of the role of ionic liquids in imparting electrocatalytic behavior to carbon paste electrode," Electroanalysis, vol. 19, no. 21, pp. 2247-2250, 2007.

[14] W. Sun, M. Yang, and K. Jiao, "Electrocatalytic oxidation of dopamine at an ionic liquid modified carbon paste electrode and its analytical application," Analytical and Bioanalytical Chemistry, vol. 389, no. 4, pp. 1283-1291, 2007.

[15] W. Sun, M. Yang, R. Gao, and K. Jiao, "Electrochemical determination of ascorbic acid in room temperature ionic liquid $\mathrm{BPPF}_{6}$ modified carbon paste electrode," Electroanalysis, vol. 19, no. 15, pp. 1597-1602, 2007.

[16] D. Wei and A. Ivaska, "Applications of ionic liquids in electrochemical sensors," Analytica Chimica Acta, vol. 607, no. 2, pp. 126-135, 2008.

[17] A. C. Franzoi, P. Migowski, J. Dupont, and I. C. Vieira, "Development of biosensors containing laccase and imidazolium bis(trifluoromethylsulfonyl)imide ionic liquid for the determination of rutin," Analytica Chimica Acta, vol. 639, no. 1-2, pp. 90-95, 2009.

[18] Y. Zhang and J. Zheng, "Sensitive voltammetric determination of rutin at an ionic liquid modified carbon paste electrode," Talanta, vol. 77, no. 1, pp. 325-330, 2008.

[19] W. Sun, M. Yang, Y. Li, Q. Jiang, S. Liu, and K. Jiao, "Electrochemical behavior and determination of rutin on a pyridinium-based ionic liquid modified carbon paste electrode," Journal of Pharmaceutical and Biomedical Analysis, vol. 48, no. 5, pp. 1326-1331, 2008.

[20] Y. Wang, H. Xiong, X. Zhang, and S. Wang, "Detection of rutin at DNA modified carbon paste electrode based on a mixture of ionic liquid and paraffin oil as a binder," Microchimica Acta, vol. 170, no. 1, pp. 27-32, 2010.

[21] Z. Zhu, X. Sun, X. Zhuang, Y. Zeng, W. Sun, and X. Huang, "Single-walled carbon nanotubes modified carbon 
ionic liquid electrode for sensitive electrochemical detection of rutin," Thin Solid Films, vol. 519, no. 2, pp. 928-933, 2010.

[22] H. Dejmkova, J. Zima, and J. Barek, "Application of carbon paste electrodes with admixed bismuth powder for the determination of 4-amino-3-nitrophenol," in Sensing in Electroanalysis, K. Vytras, K. Kalcher, and I. Svancara, Eds., vol. 3, pp. 83-89, University of Pardubice, Pardubice, Czech Republic, 2008.

[23] I. Svancara, L. Baldrianova, E. Tesarova, M. Vlcek, K. Vytras, and S. Sotiropoulos, "Microscopic studies with bismuth modified carbon paste electrodes: morphological transformation of bismuth microstructures and related observations," in Sensing in Electroanalysis, K. Vytras and K. Kalcher, Eds., vol. 2, pp. 3558, University of Pardubice, Pardubice, Czech Republic, 2007.

[24] I. Švancara, K. Vytřas, A. Bobrowski, and K. Kalcher, "Determination of arsenic at a gold-plated carbon paste electrode using constant current stripping analysis," Talanta, vol. 58, no. 1, pp. 45-55, 2002.

[25] J. Hrbac, V. Halouzka, R. Zboril, K. Papadopoulos, and T. Triantis, "Carbon electrodes modified by nanoscopic iron(III) oxides to assemble chemical sensors for the hydrogen peroxide amperometric detection," Electroanalysis, vol. 19, no. 17, pp. 1850-1854, 2007.

[26] A. A. Karyakin, O. V. Gitelmacher, and E. E. Karyakina, "A high-sensitive glucose amperometric biosensor based on Prussian Blue modified electrodes," Analytical Letters, vol. 27, pp. 2861-2869, 1994.

[27] A. A. Karyakin, E. E. Karyakina, and L. Gorton, "The electrocatalytic activity of Prussian blue in hydrogen peroxide reduction studied using a wall-jet electrode with continuous flow," Journal of Electroanalytical Chemistry, vol. 456, no. 1-2, pp. 97-104, 1998.

[28] S. Shahrokhian, M. Ghalkhani, and M. K. Amini, "Application of carbon-paste electrode modified with iron phthalocyanine for voltammetric determination of epinephrine in the presence of ascorbic acid and uric acid," Sensors and Actuators B, vol. 137, no. 2, pp. 669-675, 2009.

[29] K. Schachl, H. Alemu, K. Kalcher, J. Ježkova, I. Švancara, and K. Vytřas, "Amperometric determination of hydrogen peroxide with a manganese dioxide-modified carbon paste electrode using flow injection analysis," Analyst, vol. 122, no. 9, pp. 985-989, 1997.

[30] N. W. Beyene, P. Kotzian, K. Schachl et al., "(Bio)sensors based on manganese dioxide-modified carbon substrates: Retrospections, further improvements and applications," Talanta, vol. 64, no. 5, pp. 1151-1159, 2004.

[31] Z. Dursun and G. Nişli, "Voltammetric behavior of copper(I)oxide modified carbon paste electrode in the presence of cysteine and ascorbic acid," Talanta, vol. 63, no. 4, pp. 873878, 2004.

[32] X. Qi and R. P. Baldwin, "Liquid chromatography and electrochemical detection of organic peroxides by reduction at an iron phthalocyanine chemically modified electrode," Electroanal, vol. 5, pp. 547-554, 1993.

[33] N. Chebotareva and T. Nyokong, "First-row transition metal phthalocyanines as catalysts for water electrolysis: a comparative study," Electrochimica Acta, vol. 42, no. 23-24, pp. 3519 3524, 1997.

[34] S. Shahrokhian, M. Ghalkhani, and M. K. Amini, "Application of carbon-paste electrode modified with iron phthalocyanine for voltammetric determination of epinephrine in the presence of ascorbic acid and uric acid," Sensors and Actuators B, vol. 137, no. 2, pp. 669-675, 2009.
[35] D. Patrascu, I. David, V. David et al., "Selective voltammetric determination of electroactive neuromodulating species in biological samples using iron(II) phthalocyanine modified multi-wall carbon nanotubes paste electrode," Sensors and Actuators B, vol. 156, no. 2, pp. 731-736, 2011.

[36] A. Michalkiewicz, M. Biesaga, and K. Pyrzynska, "Solid-phase extraction procedure for determination of phenolic acids and some flavonols in honey," Journal of Chromatography A, vol. 1187, no. 1-2, pp. 18-24, 2008.

[37] M. Kotoucek, "Spectrophotometry of acid-base properties of gallocyanine methyl-ester and its derivatives," Collection of Czechoslovak Chemical Communications, vol. 40, pp. 31603168, 1975.

[38] L. A. Currie, "Nomenclature in evaluation of analytical methods including detection and quantification capabilities (IUPAC Recommendations 1995)," Pure and Applied Chemistry, vol. 67, no. 10, pp. 1699-1723, 1995.

[39] S. V. Jovanovic, S. Steenken, M. Tosic, B. Marjanovic, and M. G. Simic, "Flavonoids as antioxidants," Journal of the American Chemical Society, vol. 116, no. 11, pp. 4846-4851, 1994.

[40] R. T. Kachoosangi, G. G. Wildgoose, and R. G. Compton, "Room temperature ionic liquid carbon nanotube paste electrodes: overcoming large capacitive currents using rotating disk electrodes," Electroanalysis, vol. 19, no. 14, pp. 1483-1489, 2007.

[41] A. B. Sorokin and E. V. Kudrik, "Phthalocyanine metal complexes: versatile catalysts for selective oxidation and bleaching," Catalysis Today, vol. 159, no. 1, pp. 37-46, 2011.

[42] J. H. Zagal, S. Griveau, J. F. Silva, T. Nyokong, and F. Bedioui, "Metallophthalocyanine-based molecular materials as catalysts for electrochemical reactions," Coordination Chemistry Reviews, vol. 254, no. 23-24, pp. 2755-2791, 2010.

[43] T. Morishita, H. Yamaguchi, and K. Degi, "The contribution of polyphenols to antioxidative activity in common buckwheat and Tartary buckwheat grain," Plant Production Science, vol. 10, no. 1, pp. 99-104, 2007. 


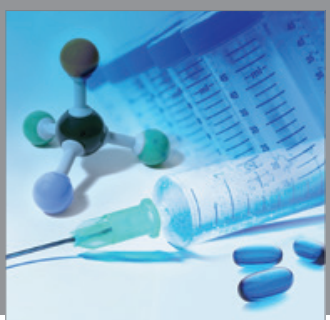

International Journal of

Medicinal Chemistry

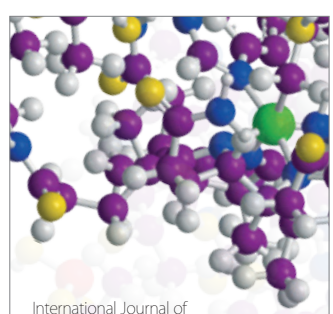

Carbohydrate Chemistry

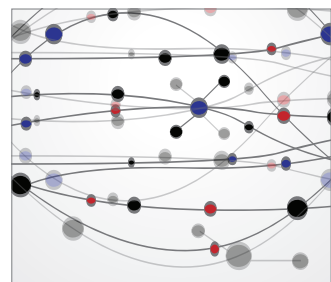

The Scientific World Journal
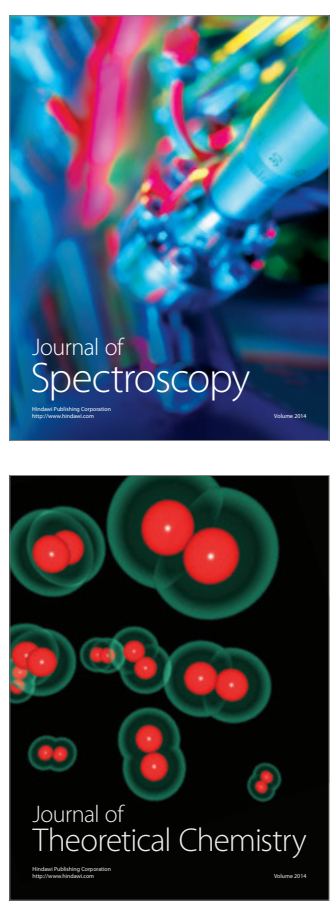
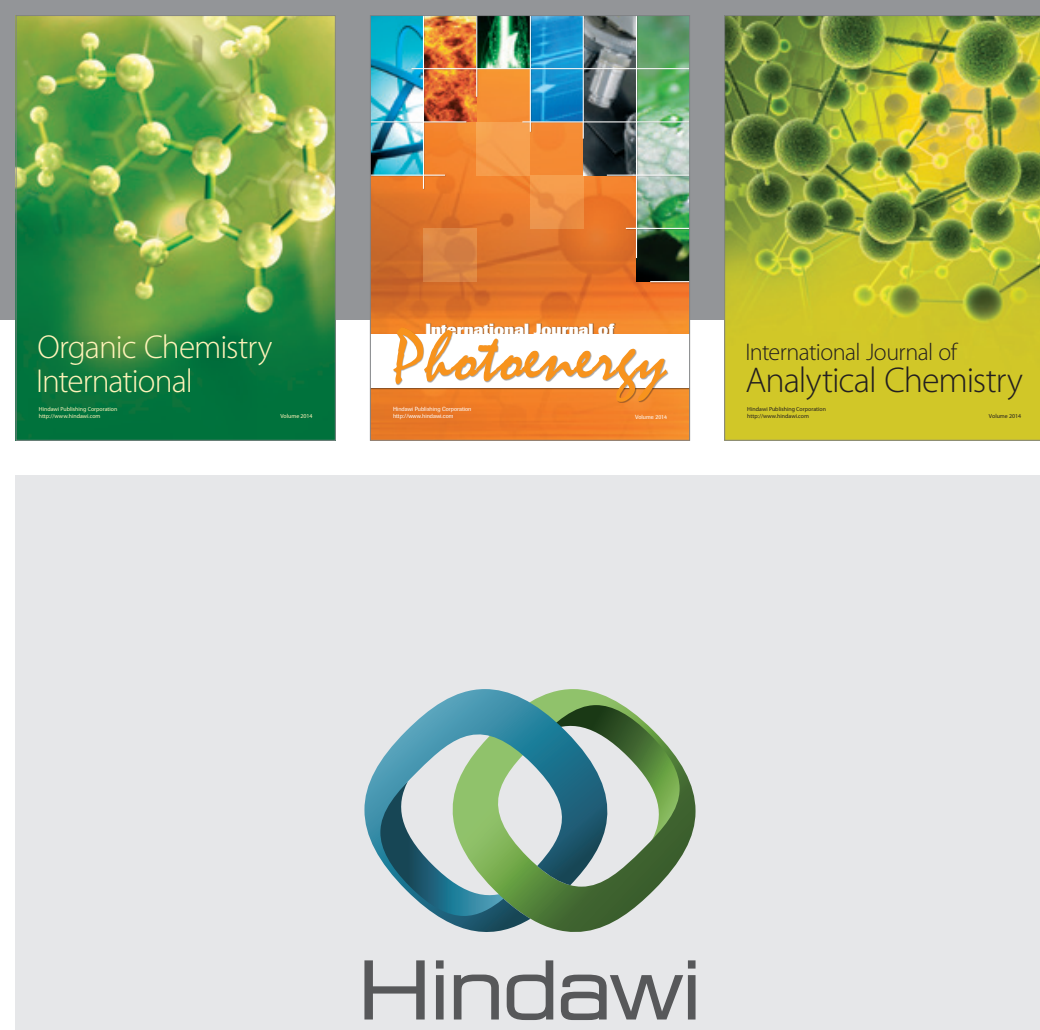

Submit your manuscripts at

http://www.hindawi.com
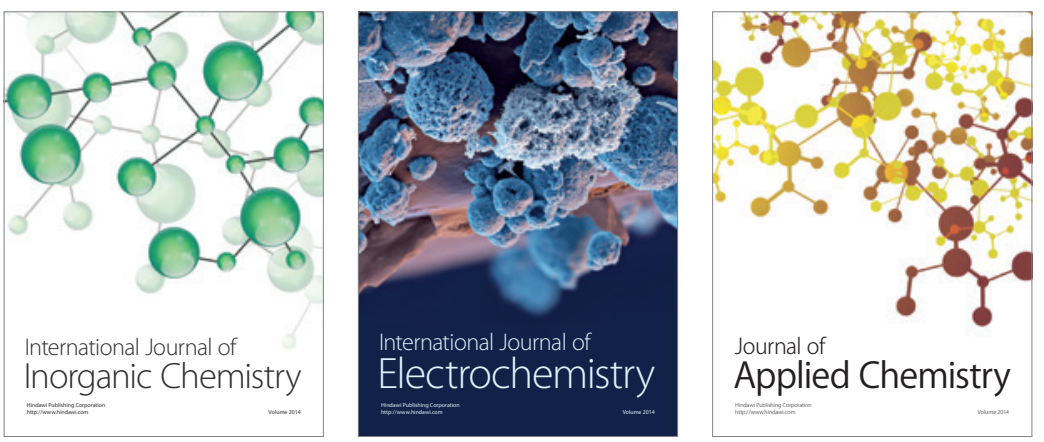

Journal of

Applied Chemistry
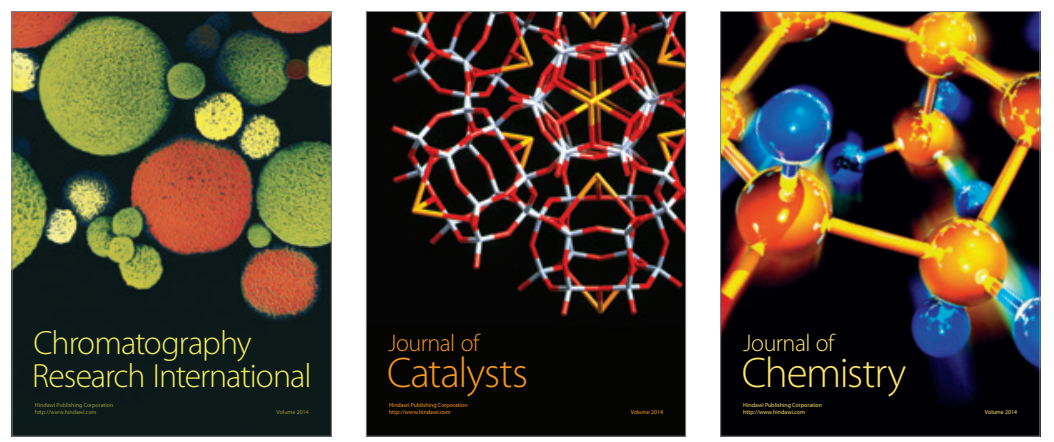
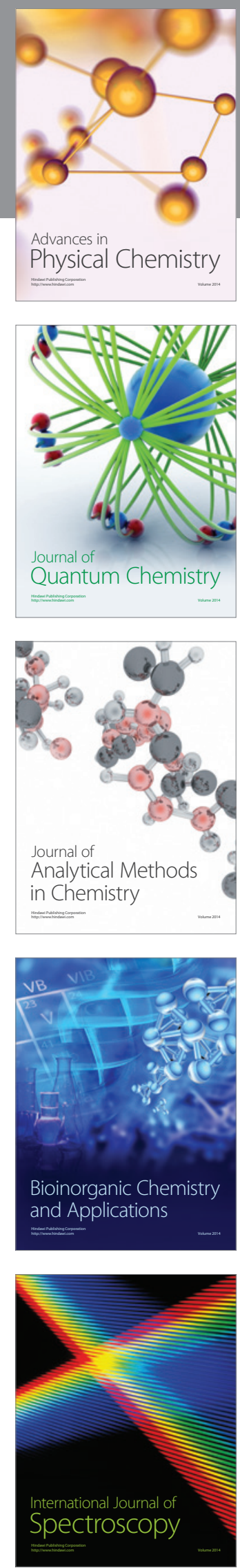